This is a post-peer-review, pre-copyedit version of an article published in Fish Physiology and Biochemistry. The final authenticated version is available online at:https://doi.org/10.1007/s10695-020-00762-3

\title{
Adequate supply of dietary taurine stimulates expression of molecular markers of growth and protein turnover in juvenile barramundi (Lates calcarifer).
}

\author{
David A. Poppi ${ }^{* 1,2}$, Stephen S. Moore ${ }^{1}$, Nicholas M. Wade ${ }^{2}$, Brett D. Glencross ${ }^{3}$.
}

${ }^{1}$ The University of Queensland, Centre for Animal Science, Queensland Alliance for Agriculture and Food Innovation, St. Lucia, QLD 4067, Australia.

${ }^{2}$ CSIRO Agriculture and Food, QLD Biosciences Precinct, St. Lucia, QLD 4067, Australia.

${ }^{3}$ Institute of Aquaculture, University of Stirling, FK9 4LA Stirling, United Kingdom.

*Corresponding Author: david.poppi@uq.net.au

Postal Address: CSIRO Agriculture and Food, Building 80, Services Road, St. Lucia, QLD 4067, Australia. Phone: +61 738335527

\begin{abstract}
A trial was conducted to investigate the effect of dietary taurine (Tau) supply on the plasma amino acid composition and hepatic expression of several genes in juvenile barramundi (Lates calcarifer) after feeding. Triplicate tanks of fish (average weight: 89.3g) were fed diets containing either a deficient (1g/kg), adequate $(8 \mathrm{~g} / \mathrm{kg})$ or excessive $(19 \mathrm{~g} / \mathrm{kg})$ level of dietary Tau. Liver tissue collected before feeding, and at two hour and four hours post-feeding, were analysed for expression of genes involved in pathways of sulphur amino acid turnover, Tau biosynthesis and transport, target of rapamycin (TOR) signalling, the somatotropic axis and protein turnover.

The treatment had no significant effect on the profiles of any amino acid in plasma collected over time after feeding, other than Tau and glycine. The expression profile of cystine and Tau synthetic genes suggested an effect of Tau excess on the metabolism of cystine. Markers of two pathways of Tau biosynthesis appear to be active in this species, providing proof that this species possesses the ability to synthesise Tau from SAA precursors. A marker for the regulation of Tau transport and homeostasis was shown to be directly regulated by Tau availability, while a link between adequate supply of Tau and TOR pathway-mediated growth stimulation was also apparent. An observed depression in expression of genes of the somatotropic axis, coupled with upregulation of the proteolytic and TOR-suppressing genes, in response to excessive Tau supply in the diet, signalled that excessive Tau may not be conducive to optimal growth in this species.
\end{abstract}

Keywords: Barramundi, Lates calcarifer, Taurine, Postprandial, Protein turnover.

\section{Introduction}

Taurine (2-aminoethane sulfonic acid) is an end-product of sulphur amino acid (SAA) metabolism and, while not incorporated into protein, is the most abundant free amino acid in the tissues of numerous animal 
species (Schuller-Levis and Park, 2003; Ripps and Shen, 2011). Accordingly, it plays a number of important functions in fish health and metabolism. Among its many roles, it is known to act as both an organic osmolyte and an antioxidant, important in responding to stress events (Huxtable, 1992; Asha and Devadasan, 2013). By conjugating with bile acids in the liver, resulting in the formation of taurocholic acid, taurine (Tau) has been shown to improve absorption of lipids (Kim et al., 2008), as well as benefitting glucose homeostasis in juvenile turbot (Scophthalmus maximus) (Zhang et al., 2019) . It also possesses the characteristics of a feeding stimulant for fish (Chatzifotis et al., 2008) which may help to overcome some of the palatability issues commonly associated with the use of plant feed ingredients in diets for carnivorous fish (McGoogan and Gatlin, 1997). Taurine has been shown to be important throughout the lifecycle of several fish species, positively affecting markers of egg quality in Nile tilapia (Oreochromis niloticus) (AlFeky et al., 2016b), as well as growth and development in red sea bream (Pagrus major) larvae (Kim et al., 2016). While many fish species possess the ability to synthesise Tau from precursor sulphur amino acids (ElSayed, 2014), supplementation, particularly to high plant protein diets, has been shown to improve growth, indicating that the synthetic capacity of the animal alone may be insufficient to meet the entire requirement (Takagi et al., 2008, 2010; Yun et al., 2012, Martins et al., 2018). Given the importance of Tau in fish health and metabolism, therefore, it is often considered to be "conditionally essential" rather than a non-essential amino acid (NEAA) in those fish possessing the capacity for synthesis. In certain species, such as yellowtail (Seriola quinqueradiata), bluefin tuna (Thunnus thynnus) and skipjack (Katsuwonus pelamis), however, this capacity has been reported to be reduced, or even absent, primarily due to variations in activity of cysteine sulfinic acid decarboxylase (CSAD) (Yokoyama et al., 2001). In these cases, Tau may be considered to be an essential component of the diet.

Consideration of the dietary Tau supply has become increasingly important in recent years given the negligible Tau content of terrestrial plant meals. If the use of these more sustainable ingredients is to be increased, accurate characterization of the dietary and metabolic requirements of Tau in the species of interest is necessary to determine its importance and the level of its supplementation required for optimal growth. Tau supplementation of non-fishmeal based diets has been linked to improved growth in a number of fish species (Salze et al., 2012, Velasquez et al., 2015, Li et al., 2016), however the exact mechanism of this stimulatory effect is so far unclear. One theory is that Tau may be sparing methionine (Met), a precursor and essential amino acid (EAA), for protein synthesis and other important physiological processes such as production of S-Adenosylmethionine (SAM) (Pinto et al., 2013).

Markers of protein turnover, and other growth-related pathways, have been used in the past to link amino acid supplementation-related growth stimulation to the mechanisms underpinning the observed response. Belghit et al. (2014), for example, reported that Met directly affected the expression level of several genes of the autophagy-lysosomal and ubiquitin-proteosome protein turnover pathways in rainbow trout (Oncorhynchus mykiss). The regulation of components of the somatotropic axis: a series of growth factors (insulin-like growth factors one and two, IGF-I and IGF-II) and related growth hormone receptors (GHRs) and binding proteins (IGFBPs) which are considered signals of growth modulation (Clemmons and 
Underwood, 1991); as well as elements of the target of rapamycin (TOR) pathway, have also been linked to amino acid supplementation in fish (Gómez-Requeni et al., 2003; Vélez et al., 2014). Rolland et al. (2015) found that Met affects these pathways "directly or indirectly" in rainbow trout and Hevrøy et al. (2007) observed a significant upregulation of several genes of the somatotropic axis in response to lysine supplementation in Atlantic salmon (Salmo salar). The effect of Tau supplementation on these pathways, however, has yet to be investigated in fish. Clarifying whether the reported apparent positive influence of Tau on growth is due to direct effects, such as signalling the initiation of specific pathways or sparing of precursor SAA, or is simply a by-product of improved overall health and metabolic functioning would be an significant step in defining the importance of this amino acid.

A Tau dose response trial conducted prior to the current experiment (Poppi et al., 2018) suggested that Tau may positively affect growth in this species, although no significant differences were seen in that study in response to variable dietary Tau. That study utilised a restricted pair-feeding approach, whereby all tanks of fish were fed an identical ration at each meal, irrespective of fish size. It was conceded by the authors that this approach may have also restricted the growth of any fish responding to increases in dietary Tau by reducing the rate of feed intake of those fish, as a percentage of body weight, limiting the divergence of the growth rates. The aim of the current experiment, then, was to determine whether any markers of growth are positively affected by dietary Tau content, which may indicate whether Tau does, in fact, impact growth pathways in this species more subtly than observed in Poppi et al. (2018), independent of the limitations of the restricted pair-feeding approach used in that study. In addition, the present study aimed to investigate the impacts of variable dietary Tau supply on sulphur amino acid and Tau turnover, indicating the role of Tau in sparing SAA, as well as further elucidating the pathways used by this species to synthesise it.

\section{Materials and Methods}

\subsection{Diets}

Three diets (Table 1), containing either a deficient (DEF; $1 \mathrm{~g} / \mathrm{kg}$ ), adequate (ADQ; $8 \mathrm{~g} / \mathrm{kg}$ ) or excessive $(\mathrm{EXC} ; 15 \mathrm{~g} / \mathrm{kg})$ dietary Tau content, were selected based on performance of fish fed these diets in a 42-day growth trial preceding this experiment (Poppi et al., 2018), where the weight of the fish increased from an average of $27 \mathrm{~g}$ to an average of $72 \mathrm{~g}$ ( $2.7 \mathrm{x}$ initial weight). The diets chosen elicited a poor growth response (DEF), the maximum response (ADQ) or contained the highest inclusion of dietary Tau (EXC), deemed excessive according to a formulation model based on the ideal protein concept with reference to lysine and the amino acid profile reported by Glencross et al. (2013).

Dietary formulations were designed to be isonitrogenous and isoenergetic. Amino acid contents were similarly intended to be equal and to exceed the amino acid requirements of barramundi according to the aforementioned formulation model, excluding glycine (used to balance the total crystalline amino acid content of the diets), total sulphur amino acids (included at an adequate level according to Poppi et al. (2017)) and Tau, the amino acid of interest. 
Diets were manufactured for the growth trial on a laboratory-scale twin-screw extruder (MPF24; Baker Perkins, Peterborough, UK), with intermeshing, co-rotating screws according to an adaptation of the protocol of Glencross et al. (2016), to produce pellets $\sim 6 \mathrm{~mm}$ in diameter.

\section{$2.2 \quad$ Fish Trial}

This experiment was conducted in accordance with the Australian Code of Practice for the Care and Use of Animals for Scientific Purposes, under the approval of the CSIRO Animal Ethics Committee (approval number: A6/2015).

Following the conclusion of a Tau dose response growth trial, described in Poppi et al. (2019), fish fed diets with deficient, adequate and excessive levels of dietary Tau (as described above) remained in triplicated 1000L tanks per treatment (nine tanks in total) and continued consumption of the same diets during an acclimation period of six days. Twenty four juvenile barramundi (Lates calcarifer) (mean initial weight: $72.1 \mathrm{~g}$ ) were housed in each tank. Diets were fed to satiety once daily for the six day period prior to the experimental feed ration determination process described below.

All feed was refrigerated $\left(<4^{\circ} \mathrm{C}\right)$, except during feeding and ration allocation.

Continuously aerated marine water $(\sim 35 \mathrm{PSU})$ of $29.5^{\circ} \mathrm{C} \pm 0.2^{\circ} \mathrm{C}$ was supplied to each tank at a rate of $\sim 3 \mathrm{~L} / \mathrm{min}$. Tank illumination was achieved using a combination of artificial lighting set at 12:12 (light:dark) and natural light of a similar photoperiod.

\subsubsection{Feed Ration Determination}

Feed intake over a five minute period (that allocated for feeding on the sampling day) was assessed for three days prior to the experimental day of the present study. In order to exclude any influence of feed intake on the postprandial response, the average intake over this period in the poorest feeding tank $(2.5 \mathrm{~g}$ fish ${ }^{1}$ ) was assigned as the ration for all tanks. This ration was offered and consumed in its entirety on the day preceding the experimental day.

\subsubsection{Sampling}

Mean weights of the fish in each treatment on the day of sampling were: DEF (86.7g), ADQ (88.7g), EXC (91.0g). Twenty four hours after the last meal, three fish were randomly selected from each tank and euthanised by an overdose of anaesthetic ( 0.2 ppt AQUI-STM). Fish were individually weighed and approximately $2 \mathrm{~mL}$ of blood was removed from the caudal vein by heparinised syringe before centrifugation at $6000 \mathrm{rpm}$ for $2 \mathrm{~min}$. Plasma was separated from the clotted material, transferred to $2 \mathrm{~mL}$ screw capped microcentrifuge tubes and placed immediately on dry ice, along with hepatic tissue samples measuring $1 \mathrm{~cm}$ x $1 \mathrm{~cm}$, before storage at $-80^{\circ} \mathrm{C}$ (zero hour control). The assigned ration was then fed after a further two hours of recovery following the zero hour sampling. Hand feeding of the experimental diets was carried out 
over a period of five minutes and staggered according to a plan designed to ensure the precision of sampling intervals of each tank. All feed was observed to have been consumed within the allotted period.

Three fish were again randomly selected from each tank one, two, four, eight, 12 and 24 hours after this meal and processed as described above. During the first three sampling points (until 4 hours postfeeding), the stomach contents of each fish was assessed. During this period, one fish out of the 81 sampled was observed to have consumed a negligible amount of feed and was replaced by an additional fish sampled at the same time, for the purposes of analyses. All remaining fish were deemed to have consumed an equivalent amount of feed.

\subsection{Chemical analyses}

Plasma samples were deproteinised according to the protocol of Davey and Ersser (1990). Briefly, equal volumes $(60 \mu \mathrm{l})$ of plasma and $500 \mu \mathrm{M}$ internal standard ( $\alpha$-Aminobutyric acid) were combined with $380 \mu \mathrm{l}$ of acetonitrile before centrifugation in an Eppendorf 5417R refrigerated centrifuge (Eppendorf AG, Hamburg, Germany) at $2200 \mathrm{~g}$ for four minutes at $4^{\circ} \mathrm{C}$. The supernatant was extracted and derivatised with 6aminoquinolyl-N-hydroxysuccinimidyl (AQC) using the Waters AccQ tag system (Waters Corporation, Milford, MA). Derivatised samples were analysed for amino acid composition using mass detection after reverse-phase ultra high-performance liquid chromatography on a Shimadzu Nexera X2 series UHPLC (Shimadzu Corporation, Kyoto, Japan) coupled with a Shimadzu 8030 Mass Spectrometer.

\subsection{Molecular analyses}

\subsubsection{RNA extraction and normalisation}

Total RNA was extracted from the frozen liver tissue taken from two fish from each of the three replicate tanks at three selected timepoints $(0 \mathrm{~h}, 2 \mathrm{~h}$ and $4 \mathrm{~h}$; based on observed peaks in the post-prandial plasma amino acid response) (two fish per tank per timepoint; $n=6$ per treatment per timepoint) using Trizol reagent (Invitrogen) in accordance with the manufacturer's instructions. Extracted RNA was then precipitated using equal volumes of isopropyl alcohol and precipitation solution ( $0.8 \mathrm{M}$ disodium citrate with 1.2M sodium chloride in ultrapure distilled water) (Green and Sambrook, 2012) before DNase digestion with the Turbo DNA-free kit (Applied Biosystems) to remove any remaining DNA. RNA quantity was assessed on a NanoDrop spectrophotometer (NanoDrop Technologies). RNA quality was then assessed using RNA nanochips (Agilent \#5067-1511) in a bioanalyser (Agilent Technologies), with visual assessment of the band integrity in the generated densitometry plots and achievement of an RNA integrity number greater than 4, used as measures of sufficient quality for RT-qPCR. All samples were normalised to a concentration of $200 \mathrm{ng} / \mu \mathrm{l}$ before cDNA synthesis. 


\subsubsection{Quantitative real-time RT-PCR}

Reverse transcription was undertaken on $1 \mu \mathrm{g}$ of total RNA using the Superscript III first strand synthesis system (Invitrogen) with $25 \mu \mathrm{M}$ oligo(dT) $)_{20}$ and $25 \mu \mathrm{M}$ random hexamers (Resuehr and Spiess, 2003), incorporating 400 pg of an exogenous Luciferase (Luc) RNA template (Promega L4561) as an internal control (De Santis et al., 2011). Real-time PCR primers for those genes not previously isolated in this species (ADO and TauT) were designed using PerlPrimer version 1.1.21 (Marshall, 2004). Sequences of gene fragments, or whole genes, within a partial, unannotated barramundi transcriptome (Hook et al., 2017), which showed significant homology with published sequences from related species, including identity with an annotated barramundi transcriptome published after these analyses were undertaken (NCBI BioProject PRJNA345597) were used to generate a series of primer pairs. Pairs with similar amplicon size (100-300bp), GC content between 50 and $60 \%$, melting temperatures close to $60^{\circ} \mathrm{C}$, and never more than $3^{\circ} \mathrm{C}$ different between primers, were chosen for the assessment. Pairs with the least chance of formation of homodimer or heterodimer complexes were selected based on assessment by PerlPrimer of the energy required to break any potential duplexes. The efficiency of each primer was optimised to between 95 and $105 \%$ using the slope of the standard curve of a PCR-amplified five-fold serial dilution of pooled cDNA. Genomic DNA contamination was excluded at this time by concurrent PCR-amplification of a pool of DNase-digested RNA. GenBank accession numbers and primer sequences for all genes are presented in Table 2.

The differential expression of selected genes of the somatotropic axis as well as Tau, sulphur amino acid and protein turnover pathways in response to the dietary treatments over time was evaluated by realtime PCR in the following fashion. The equivalent of 7.5ng of reverse-transcribed RNA was PCR-amplified following addition of 2X SYBR Green PCR Master Mix (Applied Biosystems) and 0.5 $\mu$ M RT-PCR genespecific primers. Allocation of reaction components was carried out in triplicate by an epMotion 5070 robot (Eppendorf) before being run on a Viia7 real-time PCR system (Applied Biosystems). Amplification cycle conditions were: 2 minutes at $50^{\circ} \mathrm{C}$ and 10 minutes at $95^{\circ} \mathrm{C}$, followed by 40 cycles of 15 seconds at $95^{\circ} \mathrm{C}$ and 40 seconds at $60^{\circ} \mathrm{C}$. The specificity of each primer was confirmed on completion of the reaction by assessment of dissociation melt curves for each gene. Normalisation of the cycle threshold values for each gene to that of the endogenous reference gene elongation factor $1 \alpha(\mathrm{EF} 1 \alpha)$, as previously used in several other gene expression studies with barramundi (De Santis et al., 2011; Wade et al., 2014; Salini et al., 2015) was used to assess the variation in gene expression magnitude between treatments over time. Luciferase control RNA (Promega L4561) was added as an exogenous reference to correct for differences in cDNA amplification across all samples. Amplification variation of this genes was 2.73 cycles, which did not change significantly over time.

\subsection{Statistical analysis}

All values are expressed as means with their standard errors. Prior to statistical analysis, plasma amino acid contents ( $n=9$ per treatment per timepoint) and gene expression ( $n=6$ per treatment per timepoint) data 
were log-transformed to obtain homoscedasticity. The impact of dietary treatment and time after feeding on plasma amino acid composition and the differential expression of the target genes was assessed by two-way ANOVA with Tukey's honestly significant difference $a$ posteriori test to identify differences between treatments group means within timepoints and between timepoint means within treatment. Differences between groups were considered significant at $p<0.05$. Correlations between Tau intake and both the area under the plasma Tau curve and peak plasma Tau levels were examined using Pearson's correlation test. Statistical analyses were conducted in the R-project statistical environment, version 3.1.0 (R Core Team, 2014).

\section{Results}

\subsection{Plasma amino acid contents}

Plasma amino acid contents varied significantly over time after feeding as digestion of the feed released amino acids into circulation. Peak concentrations were seen at between one (for arginine in fish fed the EXC diet - Fig. 1) and 12 hours post-feeding (for glutamic acid in fish fed the EXC diet - Fig. 2 although fluctuations were small in this amino acid), gradually returning to pre-feeding levels by 24 hours post-feeding for most amino acids. Most EAAs (Fig. 1) fluctuated significantly over time. Histidine (His), however, was the only EAA to be also be significantly affected by dietary treatment $(E X C>A D Q ; p<0.05)$, with a significant treatment:time interaction $(\mathrm{p}<0.05)$ also observed, although changes in the presence of this amino acid were small in comparison to others. The NEAAs, too, were predominantly affected only by time after the meal (Fig. 2). Glycine (Gly) and Tau (the two amino acids which varied in the dietary formulation) were additionally highly significantly affected by treatment $(\mathrm{p}<0.001)$, with the response of Tau also displaying a highly significant treatment:time interactive effect $(\mathrm{p}<0.001)$. Tau intake was highly significantly positively correlated with both the area under the plasma Tau curve (i.e. the longevity of the plasma Tau elevation $)(r=0.959, p<0.001)$ and the peak plasma Met content $(r=0.952, p<0.001)$. Additionally, plasma serine (Ser) content was highly significantly affected by treatment $(p<0.001)$. Levels of this amino acid diverged significantly two hours post-feeding, with those fish fed the DEF diet having the highest concentration of Ser in their plasma, followed by those fed the ADQ diet, then those in the EXC treatment. This pattern of response remained for the duration of the experiment. Most amino acids gradually rose to a peak and declined thereafter, as might be expected after digestion. Plasma levels of Gly in the diet containing the highest level of this amino acid (DEF) declined between the pre-feeding timepoint and the 12 hour post-feeding timepoint, returning to the pre-feeding level after a further 12 hours. The Tau plasma content followed a similar pattern, declining between the pre-feeding and four hour post-feeding timepoints before gradually rising to return to pre-feeding levels 24 hours post-feeding. 


\subsection{Gene expression}

The differential expression of the target genes was assessed in the hepatic tissue of fish sampled at two and four hours post-feeding (where peaks in plasma Tau; and a depression in plasma Tau and peak in plasma Met, respectively, were observed), as well as those taken as a pre-feeding control.

\subsubsection{Met and Cys metabolism}

The differential expression of two genes involved in the turnover of Met (methionine adenosyltransferase 1, Lc-MAT-1) and synthesis of Cys (cystathionine gamma-lyase, $L c$-CGL) in response to variation in dietary Tau was investigated and is presented in Fig.3 (A and B). Expression of both $L c$ MAT-1 and $L c$-CGL was highly significantly affected by time ( $<0.001 ; 0 \mathrm{~h}<2 \mathrm{~h} ; 0 \mathrm{~h}<4 \mathrm{~h} ; 2 \mathrm{~h}=4 \mathrm{~h})$. No effect of treatment was observed.

\subsubsection{Hypotaurine biosynthesis}

The effect of dietary Tau on the expression of genes of two hypotaurine biosynthetic pathways (cysteine dioxygenase, $L c$-CDO; cysteamine dioxygenase, $L c$-ADO; and cysteine sulfinic acid decarboxylase, $L c$-CSAD) was observed (Fig. 3, C, D, E). $L c$-CSAD expression was significantly affected by treatment $(\mathrm{p}<0.05 ; \mathrm{DEF}>\mathrm{ADQ} ; \mathrm{DEF}>\mathrm{EXC} ; \mathrm{ADQ}=\mathrm{EXC})$ and highly significantly affected by time $(\mathrm{p}<0.001$; $0 \mathrm{~h}<2 \mathrm{~h}<4 \mathrm{~h} ; 0 \mathrm{~h}<4 \mathrm{~h})$ with a significant interactive effect between the two $(\mathrm{p}<0.05$; EXC $<\mathrm{DEF}$ at the zero hour timepoint). $L c$-ADO and $L c$-CDO expression was similarly highly significantly affected by time $(\mathrm{p}<0.001$; $0 \mathrm{~h}<2 \mathrm{~h} ; 0 \mathrm{~h}<4 \mathrm{~h} ; 2 \mathrm{~h}=4 \mathrm{~h})$. Neither responded significantly to treatment, however, a significant treatment:time interactive effect $(\mathrm{p}<0.05)$ was observed for $L c$-CDO expression.

\subsubsection{Taurine transport/homeostasis}

The impact of dietary Tau on the expression of the taurine transporter gene ( $L c$-TauT), a regulator of the absorption and homeostasis of Tau was examined and is presented in Figure 3F. Expression of this gene was significantly influenced by the dietary treatment $(\mathrm{p}<0.05$; EXC $<\mathrm{DEF})$ and highly significantly affected by time after feeding $(\mathrm{p}<0.001 ; 0 \mathrm{~h}<2 \mathrm{~h} ; 0 \mathrm{~h}<4 \mathrm{~h} ; 2 \mathrm{~h}=4 \mathrm{~h})$.

\subsubsection{Somatotropic axis}

The expression of selected genes of the somatotropic axis (insulin growth factors I and II, $L c$-IGF-I, $L c$-IGF-II; and growth hormone receptor II, $L c$-GHR-II) in response to variable dietary Tau over time after feeding is presented in Figure $4(\mathrm{~A}, \mathrm{~B}, \mathrm{C})$. All examined genes of this group were highly significantly affected by diet ( $<<0.001$; DEF $<\mathrm{ADQ}>\mathrm{EXC}$; DEF=EXC). $L c$-IGF-I and $L c$-IGF-II expression were also highly significantly affected by time $(\mathrm{p}<0.001 ; 2 \mathrm{~h}<0 \mathrm{~h}>4 \mathrm{~h} ; 2 \mathrm{~h}=4 \mathrm{~h})$. Lc-GHR-II was similarly highly affected by time after feeding but between all three timepoints $(\mathrm{p}<0.001 ; 0 \mathrm{~h}>2 \mathrm{~h}>4 \mathrm{~h} ; 0 \mathrm{~h}>4 \mathrm{~h})$. 


\subsubsection{Protein degradation}

The effect of varying dietary Tau supply on the expression of two genes involved in the turnover of body protein was assessed (Fig. 4D and E)). The expression of mitochondrial ubiquitin ligase activator of NF-к $\beta-1$ ( $L c$-Mul1) remained constant throughout the analysed period, with no significant differences in expression seen in the liver tissue of fish in the different treatments. Zinc finger AN1-type domain-5 ( $L c$ -

ZFAND-5) expression, however, was highly significantly affected by time ( $<<0.001 ; 0 h>2 h>4 h ; 0 h>4 h)$. No significant main effect of treatment was seen on expression of this gene $(\mathrm{p}=0.0522)$, however, the post-hoc analysis revealed a significant difference $(\mathrm{p}<0.05)$ between fish in the EXC treatment and those in the DEF and ADQ treatments. This effect, highlighted by the highly significant treatment:time interactive effect $(p<0.001)$ was observed to be only at the two hours post-feeding timepoint $(E X C>A D Q ; E X C>D E F$; $\mathrm{DEF}=\mathrm{ADQ})$.

\subsubsection{TOR (protein synthesis) suppression signalling.}

The expression of the gene $L c$-Redd-1 (regulated in development and DNA damage response-1), a suppressor of the target of rapamycin (TOR) pathway, thought to be a major driver of growth in fish, was used as an indicator of activity of this important pathway as suggested by Wacyk et al. (2012). The effect of Tau supply on the expression of this gene is presented in Figure 4F. Highly significant effects of both treatment $(p<0.001 ; D E F>A D Q ; D E F>E X C ; A D Q<E X C)$ and time after feeding $(p<0.001 ; 0 h<2 h>4 h$; $0 \mathrm{~h}<4 \mathrm{~h})$ were observed.

\section{Discussion}

Consideration of the inclusion of Tau in the diet of carnivorous fish species has become increasingly important in recent years with the increased use of Tau deficient plant meals to replace fishmeal as the primary source of protein (Watson et al., 2015). A number of studies have been conducted to investigate the essentiality of this ingredient to various fish species (see review by Salze and Davis, 2015), with many of these observations focusing primarily on its influence on growth rate. Consideration of the underlying mechanisms behind any effect on growth is central to our understanding of why it is required, if at all, in the diet. Effects on the metabolism of Met, a precursor for Tau and the amino acid most commonly first limiting for protein synthesis in diets with high inclusion levels of non-cereal plant proteins (Jia et al., 2013), for example, may have implications for supplementation of this amino acid. In addition, understanding the pathways through which Tau impacts growth (if at all), may allow substitution of alternative dietary components (i.e. other amino acids which may be more abundant in available ingredients) which exert the same effect on these pathways. An experiment aimed at assessing the impact of dietary Tau supply on growth of barramundi (Poppi et al., 2018), observed a positive effect on growth at between 6 and $8 \mathrm{~g} \mathrm{~kg}^{-1}$ inclusion. The aim of the present study was to investigate whether this effect was reflected in selected protein turnover and growth-related pathways previously linked to dietary amino acid supplementation. A 
secondary aim was to confirm that this species does possess the ability to synthesise Tau, and to elucidate the mechanism by which it does this (if at all).

Whilst Tau is not a precursor for synthesis of other amino acids, the multitude of metabolic processes in which it has been reported to be involved in other animals suggests that its absence or excess in the diet could have an impact on the utilisation of other amino acids with which it interacts to effect these processes. Dietary Tau content, however, was observed to have little effect on the metabolism of other amino acids in the present study, consistent with the observations of a previous study with this species (Poppi et al, 2019), with reference to varying dietary Met content. It was thought that increased Tau supply in the diet may have had a sparing effect on Met, a proportion of which would otherwise have been processed for synthesis of Tau, and that this would be reflected in an increased presence, or more prolonged peak, of Met in the plasma. This, however, was not the case with no significant differences observed in Met levels at any timepoint. A primary peak in Met was observed at one hour post feeding in fish fed the EXC diet, before levels declined, then rose to a secondary peak at four hours post-feeding. Similar fluctuations were also apparent in the plasma levels of the EAAs arginine, lysine and, to a lesser extent, leucine. These amino acids were included at the highest concentrations in the EAA premix so this small initial peak may be a reflection of rapid uptake of free amino acids from the feed rather than an effect of Tau on metabolism of specific amino acids. Alam et al. (2004) suggested that binding of crystalline amino acids within a matrix using casein-gelatin could assist in negating this differential absorption and this may have been advisable in this case. Interestingly, this response was also seen in the plasma levels of the NEAA serine (Ser) which was not supplemented in the diet, so the reason for this fluctuation is not known. Levels of Ser were also observed to decrease significantly in the plasma in response to increasing dietary Tau. As a precursor for Gly synthesis, it may be that increasing Gly supplementation (which was used to replace Tau in the DEF and ADQ diets) spared Ser catabolism, increasing the circulating levels. The declining levels of Gly for the first 12 hours after feed consumption in the plasma of fish fed the DEF diet (which had the highest inclusion of Gly) was unexpected and there appears to be no logical explanation for it. The levels returned to pre-feeding concentrations by twenty four hours post-feeding which seems to suggest that this response is cyclical, though there seems no reason for excess Gly or a deficiency in Tau to precipitate this response.

One of the fates of dietary Met may be the synthesis of Tau when it is limiting in the diet (as would be expected in the DEF treatment). It was anticipated that more sulphur amino acids (SAA) would be required to be turned over for biosynthesis of Tau in fish in the DEF treatment and that this would be reflected in an upregulation of $L c$-MAT-1 (Met $\rightarrow$ SAM) and $L c$-CGL (cystathionine $\rightarrow$ Cys) in those fish. These genes were significantly upregulated in the livers of fish in all treatments two hours after the meal and remained elevated after a further two hours, reflecting the changes in plasma Met and Cys level. What was unexpected was that $L c$-MAT-1 appeared to be more highly expressed in the livers of fish in the ADQ and EXC treatments than those fed the DEF diet at two hours post feeding. It has been suggested previously that excess circulating Tau, as seen in the plasma profiles of fish fed the EXC (and, to a lesser degree, ADQ) diets reported in the present study, may spare dietary Met for other processes (Espe et al., 2012), possibly the 
most important of which is the production of S-Adenosylmethionine (SAM). The increased expression of the gene for the Cys producing enzyme $L c$-CGL at two hours post-feeding in fish fed the EXC diet and at four hours post-feeding in fish in the ADQ treatment group, however, suggests the priority may be for a cysteine metabolite further along the Met metabolic pathway, possibly glutathione or pyruvate, which play important roles in protein and energy metabolism (Wang et al., 1997; Lahnsteiner and Caberlotto, 2012). The synthesis of glutathione, specifically, has been suggested to be an important metabolic fate of Met (Li et al., 2009). Even if this were the case in the present experiment, it would be expected that $L c$-MAT-1 expression would remain constant, as any redirection of metabolites would be occurring further downstream. There is no evidence, therefore, that Tau had any sparing effect on Met requirement in the present study. Taurine has been shown to induce gastric acid secretion in rats (Huang et al., 2011) so the resulting rapid digestion may have hastened the availability of Met, although the similarity in plasma Met levels does not support this. The continual increase over time of expression of $L c$-MAT-1 in the livers of fish fed the DEF diet points to the fate of this Met likely being Tau synthesis. While patterns in the data are discussed here, no significant differences were seen which may support the assertion in Poppi et al. (2019) that expression of these genes may be regulated primarily by feed intake, rather than by the dietary amino acid profile. MAT-1, for example, may be produced in such a volume as to convert a predetermined amount of Met to SAM. Whether this SAM is destined for Tau synthesis or production of some other metabolite may be dependent on other factors. It is also acknowledged that the number of replicate samples taken at each time point for molecular analyses is relatively low, compared with similar studies (Kwasek et al., 2014; Liang et al., 2016) and that this may have contributed to the observed variation and resulting lack of significant differences in relative expression of some genes.

Similarly, it was expected that genes directly associated with the biosynthesis of Tau would be significantly affected by supplementation of Tau, in response to a reduced requirement for synthesis. Genes of components of the first taurine biosynthetic pathway (Cys $\rightarrow$ cysteine sulfinic acid $\rightarrow$ hypotaurine) showed significant upregulation at two hours post-feeding, presumably in response to increased availability of substrate for these enzymes. Expression of $L c$-CDO, catalysing production of cysteine sulfinic acid from Cys then plateaued, while expression of $L c$-CSAD, an indicator of conversion of cysteine sulfinic acid to hypotaurine, continued to increase significantly. Interestingly, the patterns of response of these two genes, as well as the gene for CGL, which is involved in the production of the Cys substrate for CDO, are quite similar, indicating the flow of metabolites along this pathway. $L c$-CSAD expression appeared to be depressed by excessive Tau intake at four hours post-feeding, indicating a negative feedback on the regulation of expression of this gene by excess circulating Tau. An interesting pattern emerged in the comparison of $L c$-ADO and $L c$-CSAD expression, the genes for the enzymes which catalyse competing pathways for hypotaurine synthesis. The CSAD-catalysed sulphinoalanine pathway is considered the primary pathway used by mammals (Schuller-Levis and Park, 2003) and has been assumed to be as such for teleost fish as well. There is evidence, however, that the cysteamine pathway, incorporating ADO, could also be significant in other animals (Ueki and Stipanuk, 2008). In the present study, both pathways appear to be 
stimulated by feed intake. $L c$-ADO appeared to respond much faster than $L c$-CSAD to feeding but remained at a lower level of expression, with $L c$-ADO expression levels peaking at two hours and $L c$-CSAD at four hours post-feeding. The pattern of response in the present study provides further proof that this species does indeed possess the ability to synthesise Tau from SAA precursors and seems to support the CSAD-mediated pathway as being the more active. The sensitivity, rather than the magnitude, of enzyme gene expression to the presence of precursors, however, has previously been linked to the capacity of fish species to synthesise Tau by Wang et al. (2016), who observed that CDO expression was more responsive to the presence of Cys in rainbow trout (which have a high taurine biosynthetic capacity) compared with Japanese flounder (with a reduced capacity for taurine biosynthesis), despite a lower overall expression of this gene in the rainbow trout. It could be argued, then, that both Tau synthetic pathways investigated in the present study may play a role in barramundi, depending on substrate availability. Quantification of the contribution of each enzyme/pathway to overall Tau biosynthesis through a combination of enzyme activity assays and more comprehensive metabolite profiling may add considerably to this assertion.

As might have been expected, taurine homeostasis was significantly affected by dietary Tau supply. $L c$-TauT was most highly expressed in the livers of fish fed the DEF diet at the pre-feeding and two-hour post-feeding timepoints, suggesting that the available taurine was in high demand in these animals, requiring dynamic transport. This difference, however, was not reflected in the plasma Tau contents which were not significantly different at the pre-feeding timepoint. It may be that cellular Tau, rather than circulating Tau, was limiting at this time, signalling production of TauT to transport Tau to areas in most demand. The significant downregulation of this gene in these fish at four hours post-feeding may be in response to the depletion of circulating Tau below a threshold for transport. This may be an indication that $L c$-TauT expression is directly regulated by Tau availability in this species, as suggested in turbot (Psetta maxima) by Wang et al. (2017), and also illustrates that hepatic Tau is rapidly used up when dietary Tau is limiting, reflecting the patterns seen in the plasma profile.

Methionine, a precursor of Tau, has been shown in the past to significantly affect factors signalling the turnover of protein in other fish species (Belghit et al., 2014), which directly or indirectly may impact overall growth stimulation. In this study, we were interested to know whether the apparent stimulatory effect of Tau inclusion on growth in this species reported in Poppi et al. (2018) was related to interactions with these same pathways, whether directly through signalling activation of the pathway or cascade, or indirectly through sparing of Met for involvement as previously outlined. Expression of the proteolytic pathway gene $L c$-ZFAND-5 was downregulated over time after the meal, being significantly higher pre-feeding than at two hours post-feeding and decreasing significantly again after a further two hours. This same pattern of response after feeding was also seen in barramundi in the study reported in Poppi et al. (2019) and seems logical considering proteolysis would be less required as circulating amino acids become increasingly available. Expression of this gene declined over time in a slower fashion in the livers of fish in the EXC treatment, and was significantly more highly expressed in fish in this treatment, compared to those fish fed the DEF and ADQ diets, at two hours post-feeding. It may suggest a stimulatory effect of excessive taurine on protein 
degradation during the brief period where circulating Tau was at its peak, although no biological reason for this is apparent. Unexpectedly, expression of $L c$-MUL-1 did not change significantly over time. This may be a reflection of the continuous nature of protein turnover (Kaushik and Seiliez, 2010). While both this gene and $L c$-ZFAND-5 are indicative of proteolysis, perhaps their respective pathways are differentially active and are stimulated or suppressed by separate stimuli. Dietary Tau level was, however, observed by de Moura et al. (2019) to have no effect on total protease activity in meagre (Argyrosomus regius). This may be indicative of the complexity of the post-transcriptional processes occurring between mRNA production (and, hence, expression of the gene of interest) and translation to associated enzymes (Panserat and Kaushik 2010), confounding interpretation of the relationship between proteolytic pathway gene expression and measurable protein degradation. In other words, Tau may stimulate expression of particular genes but not activity of the enzyme/s.

$L c$-Redd-1 expression was significantly lower in fish in the taurine adequate treatment than those in the deficient treatment at all sampling points, signalling a reduction in the suppression of TOR, and possibly suggesting a link between adequate supply of taurine and TOR pathway-mediated growth stimulation. It is not clear why expression of this gene in all treatments increased after feeding, when it might be expected that nutrient availability would stimulate growth-related pathways such as mTOR. Similarly to $L c$-ZFAND-5 expression, significant upregulation of this gene in fish fed the taurine excess diet (EXC), in comparison to those fed the adequate diet (ADQ), at both two and four hours after feeding suggests a depressive effect of taurine on growth at high levels of inclusion, as also seen in juvenile totoaba (Totoaba macdonaldi) (Satriyo et al., 2017) and larval Nile tilapia (Oreochromis niloticus) (Al-Feky et al., 2016a). Alternatively, any effect of Tau supplementation on this pathway may have been concealed by an interaction with circulating insulin, a factor not measured in this study. This relationship between amino acid supply and insulin level on the activation of the TOR cascade has been documented in other species (Lansard et al., 2010).

Variations in the dietary inclusion of other amino acids have similarly been shown to affect the expression of genes associated with the initiation and stimulation of growth processes in fish. Expression of components of the somatotropic axis, for example, were reported to be impacted by dietary Met inclusion by Rolland et al. (2015) and by dietary Lys inclusion in the study of Hevrøy et al. (2007). In the present study, the patterns of response of $L c$-IGF-I, $L c$-IGF-II and $L c$-GHR-II were similar within each timepoint. Fish in the ADQ treatment exhibited the highest relative expression of each gene at all sampling points, confirming the positive effect of adequate Tau supply on growth processes in this species, as also supported by the reduced $L c$-Redd-1 expression. Before feed was consumed, the lowest level of expression of these genes was seen in the excessive taurine treatment (EXC). After feeding, however, expression was consistently lowest in those fish fed the DEF diet. This trend is consistent with the pattern of growth observed in Poppi et al. (2018), reaffirming the connection between growth and expression of genes of the somatotropic axis. The depression in expression of these growth-related genes in response to excessive Tau supply in the diet reflects the upregulation of proteolytic and TOR-suppression markers described above, possibly further signalling that excessive Tau is not conducive to optimal growth. Whether this effect is due to a direct action 
of Tau on stimulating or suppressing expression of these genes, or is simply a reflection of differential growth regulated through alternative pathways remains unclear. While Pierce et al. (2012) showed GHR-II to be most sensitive to growth hormone and insulin supplementation in-vivo in tilapia (Oreochromis mossambicus) hepatocytes, prompting measurement of its expression in the present study, this variant is generally more abundant in the muscle, while GHR-I is the more abundant in hepatic tissue (Gabillard et al., 2006). Selection of GHR-I as an indicator of growth hormone regulation in the liver in the present study, therefore, may have yielded more meaningful results.

\section{Conclusion}

Tau appears to have a positive influence on several markers of growth or growth stimulation in barramundi. Specifically, adequate Tau may reduce the expression of the TOR suppressing gene Redd-1 and increase the expression of genes of the somatotropic axis. Quantification of the capacity of a species to synthesise Tau from precursor SAA is important in defining the essentiality of Tau supplementation in the diet. This study has confirmed that barramundi possess this capability and showed that they may be able to effect this through at least two different biosynthetic pathways, with both CSAD and ADO expression responding to feed consumption. Transport of taurine within the animal was also suggested to be directly regulated by Tau availability. It appears, then, that the growth stimulating effects of Tau which were proposed, though not significant, in Poppi et al. (2018) may have been more pronounced in the absence of the restricted pair-feeding regime, identified as a possible confounding factor in limiting the magnitude of growth divergence of fish in that study. While Tau may not be required in the diet per se, supplementation may be advantageous where sufficient SAA precursor supply is limiting.

\section{Acknowledgements}

The authors wish to acknowledge the staff of the CSIRO Bribie Island Aquaculture Centre (BIRC): Mr. Simon Irvin, Ms. Natalie Habilay, Mr. Isaak Kadel and Mr. Joel Slinger for their assistance in the collection of samples and Mr. David Blyth in the preparation of the diets. This research did not receive a specific grant but was funded by the Commonwealth Scientific and Industrial Research Organisation (CSIRO) and The Queensland Alliance for Agriculture and Food Innovation. David Poppi received support through an Australian Government Research Training Program Scholarship.

Conflict of Interest: The authors state that they have no conflict of interest.

\section{References}

Al-Feky, S.S.A., El-Sayed, A.F.M., Ezzat, A.A., 2016a. Dietary taurine improves reproductive performance of Nile tilapia (Oreochromis niloticus) broodstock. Aquac. Nutr. 22, 392-399.

Al-Feky, S.S.A., El-Sayed, A.F.M., Ezzat, A.A., 2016b. Dietary taurine enhances growth and feed utilization in larval Nile tilapia (Oreochromis niloticus) fed soybean meal-based diets. Aquac. Nutr. 22, 457-464. 
Alam, M., Teshima, S., Koshio, S., Ishikawa, M., 2004. Effects of supplementation of coated crystalline amino acids on growth performance and body composition of juvenile kuruma shrimp Marsupenaeus japonicus. Aquaculture nutrition. 10, 309-316.

Ambardekar, A.A., Reigh, R.C., Williams, M.B., 2009. Absorption of amino acids from intact dietary proteins and purified amino acid supplements follows different time-courses in channel catfish (Ictalurus punctatus). Aquaculture. 291, 179-187.

Asha, K., Devadasan, K., 2013. Protective effect of taurine on the mitochondria of albino rats induced with fulminant hepatic failure. Biomedicine \& Preventive Nutrition. 3, 279-283.

Belghit, I., Skiba-Cassy, S., Geurden, I., Dias, K., Surget, A., Kaushik, S., Panserat, S., Seiliez, I., 2014. Dietary methionine availability affects the main factors involved in muscle protein turnover in rainbow trout (Oncorhynchus mykiss). British Journal of Nutrition, 1-11.

Chatzifotis, S., Polemitou, I., Divanach, P., Antonopoulou, E., 2008. Effect of dietary taurine supplementation on growth performance and bile salt activated lipase activity of common dentex, Dentex dentex, fed a fish meal/soy protein concentrate-based diet. Aquaculture. 275, 201-208.

Clemmons, D.R., Underwood, L.E., 1991. Nutritional regulation of IGF-I and IGF binding proteins. Annual review of nutrition. 11, 393-412.

Davey, J.F., Ersser, R.S., 1990. Amino acid analysis of physiological fluids by high-performance liquid chromatography with phenylisothiocyanate derivatization and comparison with ion-exchange chromatography. Journal of Chromatography B: Biomedical Sciences and Applications. 528, 9-23.

de Moura, L.B., Diógenes, A.F., Campelo, D.A.V., de Almeida, F.L.A., Pousão-Ferreira, P.M., Furuya, W.M., Peres, H., Oliva-Teles, A., 2019. Nutrient digestibility, digestive enzymes activity, bile drainage alterations and plasma metabolites of meagre (Argyrosomus regius) feed high plant protein diets supplemented with taurine and methionine. Aquaculture 511, 734231.

De Santis, C., Smith-Keune, C., Jerry, D.R., 2011. Normalizing RT-qPCR data: are we getting the right answers? An appraisal of normalization approaches and internal reference genes from a case study in the finfish Lates calcarifer. Marine biotechnology. 13, 170-180.

El-Sayed, A.F.M., 2014. Is dietary taurine supplementation beneficial for farmed fish and shrimp? A comprehensive review. Rev. Aquac. 6, 241-255.

Espe, M., Ruohonen, K., El-Mowafi, A., 2012. Effect of taurine supplementation on the metabolism and body lipid-to-protein ratio in juvenile Atlantic salmon (Salmo salar). Aquaculture Research. 43, 349360 .

Gabillard, J.C., Kamangar, B.B., Montserrat, N., 2006. Coordinated regulation of the GH/IGF system genes during refeeding in rainbow trout (Oncorhynchus mykiss). J. Endocrinol. 191, 15-24.

Glencross, B., Wade, N., Morton, K., 2013. Lates calcarifer Nutrition and Feeding Practices. in: Jerry, D.R. (Ed.), Biology and Culture of Asian Seabass Lates Calcarifer. CRC Press, pp. 178-228.

Glencross, B., Blyth, D., Irvin, S., Bourne, N., Campet, M., Boisot, P., Wade, N.M., 2016. An evaluation of the complete replacement of both fishmeal and fish oil in diets for juvenile Asian seabass, Lates calcarifer. Aquaculture. 451, 298-309. 
Gómez-Requeni, P., Mingarro, M., Kirchner, S., Calduch-Giner, J., Médale, F., Corraze, G., Panserat, S., Martin, S., Houlihan, D., Kaushik, S., 2003. Effects of dietary amino acid profile on growth performance, key metabolic enzymes and somatotropic axis responsiveness of gilthead sea bream (Sparus aurata). Aquaculture. 220, 749-767.

Green, M., Sambrook, J., 2012. Molecular cloning: a laboratory manual, Cold Spring Harbor Laboratory Press. New York.

Hevrøy, E., El-Mowafi, A., Taylor, R., Olsvik, P., Norberg, B., Espe, M., 2007. Lysine intake affects gene expression of anabolic hormones in Atlantic salmon, Salmo salar. General and comparative endocrinology. 152, 39-46.

Hook, S.E., Kroon, F.J., Metcalfe, S., Greenfield, P.A., Moncuquet, P., McGrath, A., Smith, R., Warne, M.S.J., Turner, R.D., McKeown, A., 2017. Global transcriptomic profiling in barramundi (Lates calcarifer) from rivers impacted by differing agricultural land uses. Environmental Toxicology and Chemistry. 36, 103-112.

Huang, K.-H., Chang, C.-C., Ho, J.-D., Lu, R.-H., Tsai, L.H., 2011. Role of taurine on acid secretion in the rat stomach. Journal of biomedical science. $18,1$.

Huxtable, R., 1992. Physiological actions of taurine. Physiological reviews. 72, 101-163.

Jia, P., Xue, M., Zhu, X., Liu, H.-Y., Wu, X.-F., Wang, J., Zheng, Y.-H.a., Xu, M., 2013. Effects of dietary methionine levels on the growth performance of juvenile gibel carp (Caeassius auratus gibelio). Acta Hydrobiologica Sinica. 37, 217-226.

Kaushik, S.J., Seiliez, I., 2010. Protein and amino acid nutrition and metabolism in fish: current knowledge and future needs. Aquaculture Research. 41, 322-332.

Kim, S.K., Matsunari, H., Nomura, K., Tanaka, H., Yokoyama, M., Murata, Y., Ishihara, K., Takeuchi, T., 2008. Effect of dietary taurine and lipid contents on conjugated bile acid composition and growth performance of juvenile Japanese flounder Paralichthys olivaceus. Fisheries Science. 74, 875-881.

Kim, Y.S., Sasaki, T., Awa, M., Inomata, M., Honryo, T., Agawa, Y., Ando, M., Sawada, Y., 2016. Effect of dietary taurine enhancement on growth and development in red sea bream Pagrus major larvae. Aquac. Res. 47, 1168-1179.

Kwasek, K., Terova, G., Lee, B.J., Bossi, E., Saroglia, M., Dabrowski, K., 2014. Dietary methionine supplementation alters the expression of genes involved in methionine metabolism in salmonids. Aquaculture 433, 223-228.

Lahnsteiner, F., Caberlotto, S., 2012. Motility of gilthead seabream Sparus aurata spermatozoa and its relation to temperature, energy metabolism and oxidative stress. Aquaculture. 370, 76-83.

Lansard, M., Panserat, S., Plagnes-Juan, E., Seiliez, I., Skiba-Cassy, S., 2010. Integration of insulin and amino acid signals that regulate hepatic metabolism-related gene expression in rainbow trout: role of TOR. Amino acids. 39, 801-810.

Li, P., Mai, K., Trushenski, J., Wu, G., 2009. New developments in fish amino acid nutrition: towards functional and environmentally oriented aquafeeds. Amino acids. 37, 43-53. 
Li, M., Lai, H., Li, Q., Gong, S., Wang, R., 2016. Effects of dietary taurine on growth, immunity and hyperammonemia in juvenile yellow catfish Pelteobagrus fulvidraco fed all-plant protein diets. Aquaculture 450, 349-355.

Liang, H., Ren, M., Habte-Tsion, H.M., Ge, X., Xie, J., Mi, H., Xi, B., Miao, L., Liu, B., Zhou, Q., Fang, W., 2016. Dietary arginine affects growth performance, plasma amino acid contents and gene expressions of the TOR signaling pathway in juvenile blunt snout bream, Megalobrama amblycephala. Aquaculture $461,1-8$.

Marshall, O.J., 2004. PerlPrimer: cross-platform, graphical primer design for standard, bisulphite and realtime PCR. Bioinformatics. 20, 2471-2472.

Martins, N., Estevão-Rodrigues, T., Diógenes, A.F., Diaz-Rosales, P., Oliva-Teles, A., Peres, H., 2018. Taurine requirement for growth and nitrogen accretion of European sea bass (Dicentrarchus labrax, L.) juveniles. Aquaculture 494, 19-25.

McGoogan, B., Gatlin, D., 1997. Effects of replacing fish meal with soybean meal in diets for red drum Sciaenops ocellatus and potential for palatability enhancement. Journal of the World Aquaculture Society. 28, 374-385.

Panserat, S., Kaushik, S.J., 2010. Regulation of gene expression by nutritional factors in fish. Aquac. Res. $41,751-762$.

Pierce, A.L., Breves, J.P., Moriyama, S., Uchida, K., Grau, E.G., 2012. Regulation of growth hormone (GH) receptor (GHR1 and GHR2) mRNA level by GH and metabolic hormones in primary cultured tilapia hepatocytes. Gen. Comp. Endocrinol. 179, 22-29.

Pinto, W., Figueira, L., Santos, A., Barr, Y., Helland, S., Dinis, M.T., Aragão, C., 2013. Is dietary taurine supplementation beneficial for gilthead seabream (Sparus aurata) larvae? Aquaculture. 384-387, 1-5.

Poppi, D.A., Moore, S.S., Glencross, B.D., 2017. Redefining the requirement for total sulfur amino acids in the diet of barramundi (Lates calcarifer) including assessment of the cystine replacement value. Aquaculture. 471, 213-222.

Poppi, D.A., Glencross, B.D., Moore, S.S., 2018. The effect of taurine supplementation to a plant-based diet for barramundi (Lates calcarifer) with varying methionine content 1340-1350. https://doi.org/10.1111/anu.12671

Poppi, D.A., Moore, S.S., Wade, N.M., Glencross, B.D., 2019. Postprandial plasma free amino acid profile and hepatic gene expression in juvenile barramundi (Lates calcarifer) is more responsive to feed consumption than to dietary methionine inclusion. Aquaculture 501, 345-358. https://doi.org/10.1016/j.aquaculture.2018.11.044

R Core Team, 2014. R: A language and environment for statistical computing. R Foundation for Statistical Computing, Vienna, Austria. URL http://www.R-project.org/.

Resuehr, D., Spiess, A.-N., 2003. A real-time polymerase chain reaction-based evaluation of cDNA synthesis priming methods. Analytical biochemistry. 322, 287-291. 
Ripps, H., Shen, W., 2011. Review: Taurine: A “very essential” amino acid. Molecular vision. 18, 26732686.

Rolland, M., Dalsgaard, J., Holm, J., Gómez-Requeni, P., Skov, P.V., 2015. Dietary methionine level affects growth performance and hepatic gene expression of GH-IGF system and protein turnover regulators in rainbow trout (Oncorhynchus mykiss) fed plant protein-based diets. Comparative Biochemistry and Physiology Part B: Biochemistry and Molecular Biology. 181, 33-41.

Salini, M.J., Turchini, G.M., Wade, N.M., Glencross, B.D., 2015. Rapid effects of essential fatty acid deficiency on growth and development parameters and transcription of key fatty acid metabolism genes in juvenile barramundi (Lates calcarifer). British Journal of Nutrition. 114, 1784-1796.

Salze, G., McLean, E., Craig, S.R., 2012. Dietary taurine enhances growth and digestive enzyme activities in larval cobia. Aquaculture. 362, 44-49.

Salze, G.P., Davis, D.A., 2015. Taurine: a critical nutrient for future fish feeds. Aquaculture. 437, 215-229.

Satriyo, T.B., Galaviz, M.A., Salze, G., López, L.M., 2017. Assessment of dietary taurine essentiality on the physiological state of juvenile Totoaba macdonaldi. Aquac. Res. 48, 5677-5689.

Schuller-Levis, G.B., Park, E., 2003. Taurine: new implications for an old amino acid. FEMS microbiology letters. 226, 195-202.

Takagi, S., Murata, H., Goto, T., Endo, M., Yamashita, H., Ukawa, M., 2008. Taurine is an essential nutrient for yellowtail Seriola quinqueradiata fed non-fish meal diets based on soy protein concentrate. Aquaculture 280, 198-205.

Takagi, S., Murata, H., Goto, T., Hatate, H., Endo, M., Yamashita, H., Miyatake, H., Ukawa, M., 2010. Necessity of dietary taurine supplementation for preventing green liver symptom and improving growth performance in yearling red sea bream Pagrus major fed nonfishmeal diets based on soy protein concentrate. Fish. Sci. 76, 119-130.

Ueki, I., Stipanuk, M.H., 2008. 3T3-L1 Adipocytes and Rat Adipose Tissue Have a High Capacity for Taurine Synthesis by the Cysteine Dioxygenase/Cysteinesulfinate Decarboxylase and Cysteamine Dioxygenase Pathways. J. Nutr. 139, 207-214.

Vélez, E.J., Lutfi, E., Jiménez-Amilburu, V., Riera-Codina, M., Capilla, E., Navarro, I., Gutiérrez, J., 2014. IGF-I and amino acids effects through TOR signaling on proliferation and differentiation of gilthead sea bream cultured myocytes. General and comparative endocrinology. 205, 296-304.

Velasquez, A., Pohlenz, C., Barrows, F.T., Gaylord, T.G., Gatlin, D.M., 2015. Assessment of taurine bioavailability in pelleted and extruded diets with red drum Sciaenops ocellatus. Aquaculture 449, 2-7.

Wacyk, J., Powell, M., Rodnick, K., Overturf, K., Hill, R.A., Hardy, R., 2012. Dietary protein source significantly alters growth performance, plasma variables and hepatic gene expression in rainbow trout (Oncorhynchus mykiss) fed amino acid balanced diets. Aquaculture. 356-357, 223-234.

Wade, N.M., Skiba-Cassy, S., Dias, K., Glencross, B.D., 2014. Postprandial molecular responses in the liver of the barramundi, Lates calcarifer. Fish physiology and biochemistry. 40, 427-443. 
Wang, S.-T., Chen, H.-W., Sheen, L.-Y., Lii, C.-K., 1997. Methionine and cysteine affect glutathione level, glutathione-related enzyme activities and the expression of glutathione $\mathrm{S}$-transferase isozymes in rat hepatocytes. The Journal of nutrition. 127, 2135-2141.

Wang, X., He, G., Mai, K., Xu, W., Zhou, H., 2017. Molecular cloning and characterization of taurine transporter from turbot (Psetta maxima) and its expression analysis regulated by taurine in vitro. Aquaculture Research, 1-11.

Wang, X., He, G., Mai, K., Xu, W., Zhou, H., 2016. Differential regulation of taurine biosynthesis in rainbow trout and Japanese flounder. Sci. Rep. 6, 1-13.

Watson, A.M., Barrows, F.T., Allen, R., 2015. The Importance of Taurine and n-3 Fatty Acids in Cobia, Rachycentron canadum, Nutrition. Bull. Fish. Res. Agen. No. 40, 51-59.

Yokoyama, M., Takeuchi, T., Park, G., Nakazoe, J., 2001. Hepatic cysteinesulphinate decarboxylase activity in fish. Aquaculture Research. 32, 216-220.

Yun, B., Ai, Q., Mai, K., Xu, W., Qi, G., Luo, Y., 2012. Synergistic effects of dietary cholesterol and taurine on growth performance and cholesterol metabolism in juvenile turbot (Scophthalmus maximus L.) fed high plant protein diets. Aquaculture. 324, 85-91.

Zhang, Y., Wei, Z., Liu, G., Deng, K., Yang, M., Pan, M., Gu, Z., Liu, D., Zhang, W., Mai, K., 2019. Synergistic effects of dietary carbohydrate and taurine on growth performance, digestive enzyme activities and glucose metabolism in juvenile turbot Scophthalmus maximus L. Aquaculture 499, 32-41. 
Table 1. Formulations and analysed compositions of experimental diets.

\begin{tabular}{|c|c|c|c|}
\hline & DEF & $\mathrm{ADQ}$ & EXC \\
\hline \multicolumn{4}{|l|}{ Ingredients $\left(g \mathrm{~kg}^{-1}\right)$} \\
\hline Fishmeal $^{1}$ & 150 & 150 & 150 \\
\hline SPC & 490 & 490 & 490 \\
\hline Fish oil $^{2}$ & 100 & 100 & 100 \\
\hline Cellulose & 67 & 67 & 67 \\
\hline Pregel Starch & 53 & 53 & 53 \\
\hline $\mathrm{CaHPO}_{4}$ & 20 & 20 & 20 \\
\hline Vit. and Min. Premix ${ }^{3}$ & 6 & 6 & 6 \\
\hline Choline chloride ${ }^{4}$ & 1 & 1 & 1 \\
\hline $\operatorname{Marker}\left(\mathrm{Y}_{2} \mathrm{O}_{3}\right)$ & 1 & 1 & 1 \\
\hline DL-Met & 6.5 & 6.5 & 6.5 \\
\hline L-Taurine & 0 & 8 & 19 \\
\hline L-Glycine & 25.5 & 17.5 & 6.5 \\
\hline EAA Premix $^{5}$ & 80 & 80 & 80 \\
\hline \multicolumn{4}{|c|}{ Composition as determined ( $\mathrm{g} \mathrm{kg}^{-1} \mathrm{DM}$ unless otherwise stated) } \\
\hline Dry matter ( $\mathrm{g} \mathrm{kg}^{-1}$ as is) & 971 & 971 & 968 \\
\hline Crude Protein & 582 & 569 & 558 \\
\hline Digestible Protein & 484 & 474 & 446 \\
\hline Lipid & 116 & 114 & 117 \\
\hline Ash & 75.6 & 74.5 & 74.3 \\
\hline Gross Energy ( $\left.\mathrm{MJ} \mathrm{kg}^{-1} \mathrm{DM}\right)$ & 21.9 & 21.6 & 21.6 \\
\hline $\mathrm{DE}\left(\mathrm{MJ} \mathrm{kg}^{-1} \mathrm{DM}\right)$ & 16.9 & 16.6 & 16.2 \\
\hline \multicolumn{4}{|l|}{ EAAs } \\
\hline $\operatorname{Arg}$ & 40 & 39 & 38 \\
\hline His & 10 & 11 & 10 \\
\hline Ile & 26 & 27 & 27 \\
\hline Leu & 42 & 44 & 46 \\
\hline Lys & 37 & 38 & 36 \\
\hline Met & 13 & 13 & 13 \\
\hline Cys & 5 & 5 & 5 \\
\hline Phe & 28 & 29 & 28 \\
\hline Thr & 28 & 28 & 28 \\
\hline Val & 32 & 33 & 33 \\
\hline Tau & 1 & 8 & 15 \\
\hline
\end{tabular}

${ }^{1}$ Fishmeal: Chilean anchovy meal, Ridley Aquafeeds, Narangba, QLD, Australia.

${ }^{2}$ Fish (anchovy) oil: Ridley Aquafeeds, Narangba, QLD, Australia.

${ }^{3}$ Vitamin and mineral premix includes (IU/kg or g/kg of premix): retinol, $2.5 \mathrm{MIU}$; cholecalciferol, 0.25 MIU; $\alpha$-tocopherol,16.7g; Vitamin K3,1.7g; thiamin, 2.5g; riboflavin, 4.2g; niacin, 25g; pantothenic acid, $8.3 \mathrm{~g}$; pyridoxine, 2.0g; folate, 0.8g; Vitamin B12, 0.005g; Biotin, $0.17 \mathrm{~g}$; Vitamin C, 75g; Inositol, 58.3g; Ethoxyquin, 20.8g; Copper, 2.5g; Ferrous iron, 10.0g; Magnesium, 16.6g; Manganese, 15.0g; Zinc, 25.0g.

${ }^{4}$ Choline chloride $70 \%$ corn cob

${ }^{5}$ Essential amino acid premix consisting of ( $\mathrm{g} \mathrm{kg}^{-1}$ of premix): L-Isoleucine, 75.0g; L-Valine, 125.0g; L-Leucine, $187.5 \mathrm{~g}$; L-Phenylalanine, 87.5g; LThreonine, 150.0g; L-Lysine, 187.5g; L-Arginine, 187.5g 
Table 2. Target genes of sulphur amino acid and protein turnover; and growth in barramundi, and the primer sequences used in the qPCR assays of their expression.

\begin{tabular}{|c|c|c|c|c|}
\hline Target Gene $^{1}$ & Accession Number & Primer Name & Sequence & Length \\
\hline \multicolumn{5}{|c|}{ Met and Cys metabolism } \\
\hline \multirow[t]{2}{*}{$L c-M A T-1$} & XM_018678413 & MAT1 qPCR F1 & TGTCAATCTCCTTGTTCACCT & 21 \\
\hline & & MAT1 qPCR R1 & GCCTCTTCAGATTCAGTTCC & 20 \\
\hline \multirow[t]{2}{*}{$L c-C G L$} & XM_018673132 & CGL qPCR F2 & CACAAGACGAGCAGAACGAC & 20 \\
\hline & & CGL qPCR R2 & CACCACAGCCATTGACTTCC & 20 \\
\hline \multicolumn{5}{|l|}{ Tau metabolism } \\
\hline \multirow[t]{2}{*}{$L c-C D O$} & XM_018674402 & CDO- qPCR F2 & GTTGCCTACATAAATGACTCCA & 22 \\
\hline & & CDO- qPCR R2 & CTGTCCTCTGGTCAAAGGTC & 20 \\
\hline \multirow[t]{2}{*}{$L c-C S A D$} & XM_018666199 & CSAD qPCR F1 & GTACATTCCACCAAGTCTGAG & 21 \\
\hline & & CSAD qPCR R1 & CCCAGGTTGTGTATCTCATCC & 21 \\
\hline \multirow[t]{2}{*}{$L c-A D O$} & XM_018660792 & ADO qPCR F5 & AGCCTGTTAGTACTGTGATCC & 21 \\
\hline & & ADO qPCR R5 & AGACATCAATGCTGAAATGGAC & 22 \\
\hline \multicolumn{5}{|l|}{ Somatotropic axis } \\
\hline \multirow[t]{2}{*}{$L c-I G F-I$} & XM_018697285 & IGF-1 qPCR F2 & CTGTATCTCCTGTAGCCACAC & 21 \\
\hline & & IGF-1 qPCR R2 & AGCCATAGCCTGGTTTACTG & 20 \\
\hline \multirow[t]{2}{*}{$L c-I G F-I I$} & XM_018664155 & IGF-II qPCR F1 & AGTATTCCAAATACGAGGTGTG & 22 \\
\hline & & IGF-II qPCR R1 & GAAGATAACCTGCTCCTGTG & 20 \\
\hline \multirow[t]{2}{*}{$L c-G H R-I I$} & XM_018702499 & GHR-2 qPCR F2 & CGTCCATATCCCATCTAAAGTGTC & 24 \\
\hline & & GHR-2 qPCR R2 & GTCATTCTGCTCCTCAATGTC & 21 \\
\hline \multicolumn{5}{|l|}{ Proteolysis } \\
\hline \multirow[t]{2}{*}{$L c-M U L-1$} & XM_018686248 & Mul1 qPCR F1 & GGCTTCCGTTATTTCCTCAC & 20 \\
\hline & & Mul1 qPCR R1 & TGCTCTCCTCTATGTTAAGTTCAC & 24 \\
\hline \multirow[t]{2}{*}{$L c-Z F A N D-5$} & XM_018669382 & ZFAND5 qPCR F1 & CTAGAGCCTGTTGTAAGCCA & 20 \\
\hline & & ZFAND5 qPCR R1 & CTCGGCCTTGTAATCATAGGG & 21 \\
\hline \multicolumn{5}{|c|}{ TOR suppression signaling } \\
\hline \multirow[t]{2}{*}{ Lc-Redd-1 } & XM_018699192 & Redd1 qPCR F2 & TTTCAGCACATCCACTAACGG & 21 \\
\hline & & Redd1 qPCR R2 & СCACTACTTCTTTCAGGATTGTC & 23 \\
\hline \multicolumn{5}{|l|}{ Control genes } \\
\hline \multirow[t]{2}{*}{ Luc } & na & Luc qPCR F & GGTGTTGGGCGCGTTATTTA & 20 \\
\hline & & Luc qPCR R & CGGTAGGCTGCGAAATGC & 18 \\
\hline \multirow[t]{2}{*}{$E F 1 \alpha$} & GQ_507427 & Lcal EF $1 \alpha \mathrm{F}$ & AAATTGGCGGTATTGGAAC & 19 \\
\hline & & Lcal EF1 $\alpha$ R & GGGAGCAAAGGTGACGAC & 18 \\
\hline
\end{tabular}

${ }^{I} M A T$-1, methionine adenosyltransferase-1; $C G L$, cystathionine- $\gamma$-lyase; $C D O$, cysteine dioxygenase; $C S A D$, cysteine sulphinic acid decarboxylase; $A D O$, cysteamine dioxygenase; $I G F-I$, insulin growth factor-I; IGF-II, insulin growth factor-II; $G H R$-II, growth hormone receptor-II; $M U L-1$, mitochondrial ubiquitin ligase activator of NF- $\kappa \beta-1 ; Z F A N D-5$, zinc finger AN1-type domain-5; Redd-1, regulated in development and DNA damage response-1; Luc, luciferase; $E F 1 \alpha$, elongation factor $1 \alpha$. 

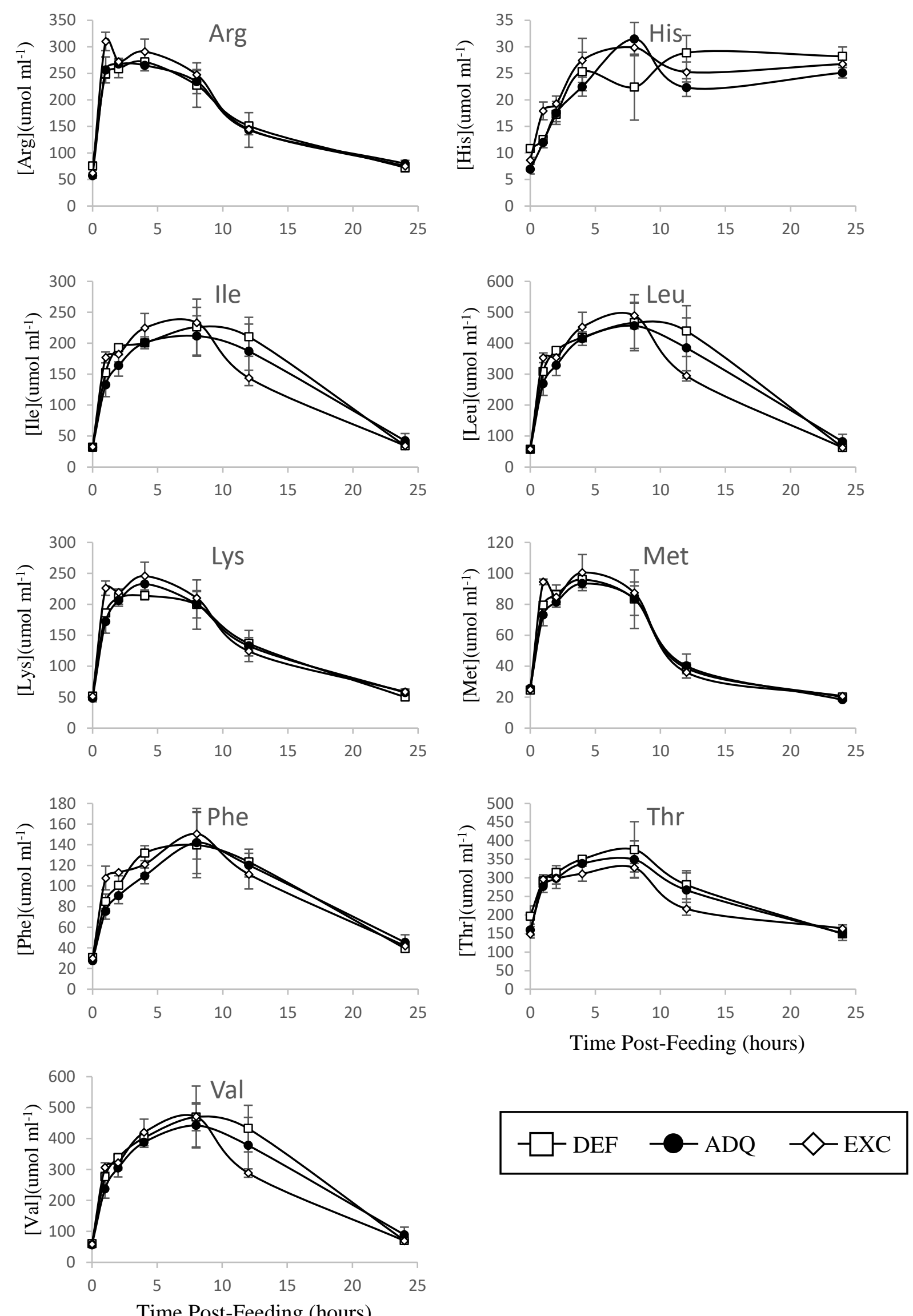

Figure 1. Concentrations of individual essential amino acids present in the plasma of juvenile barramundi over a 24 hour period following ingestion of a single meal containing either a deficient (DEF), adequate (ADQ) or excessive (EXC) dietary taurine content. 

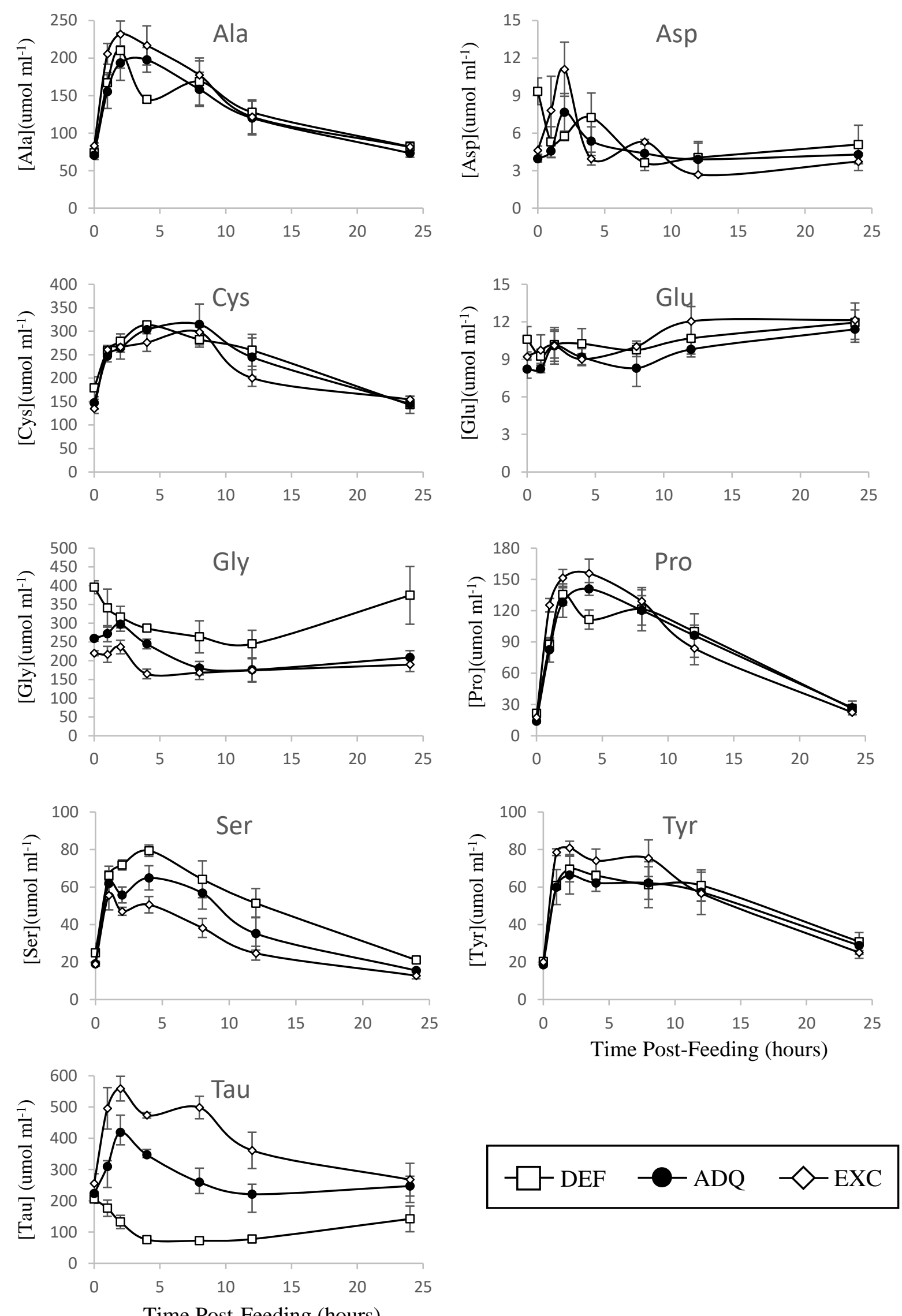

Figure 2. Concentrations of individual non-essential amino acids present in the plasma of juvenile barramundi over a 24 hour period following ingestion of a single meal containing either a deficient (DEF), adequate (ADQ) or excessive (EXC) dietary taurine content. 

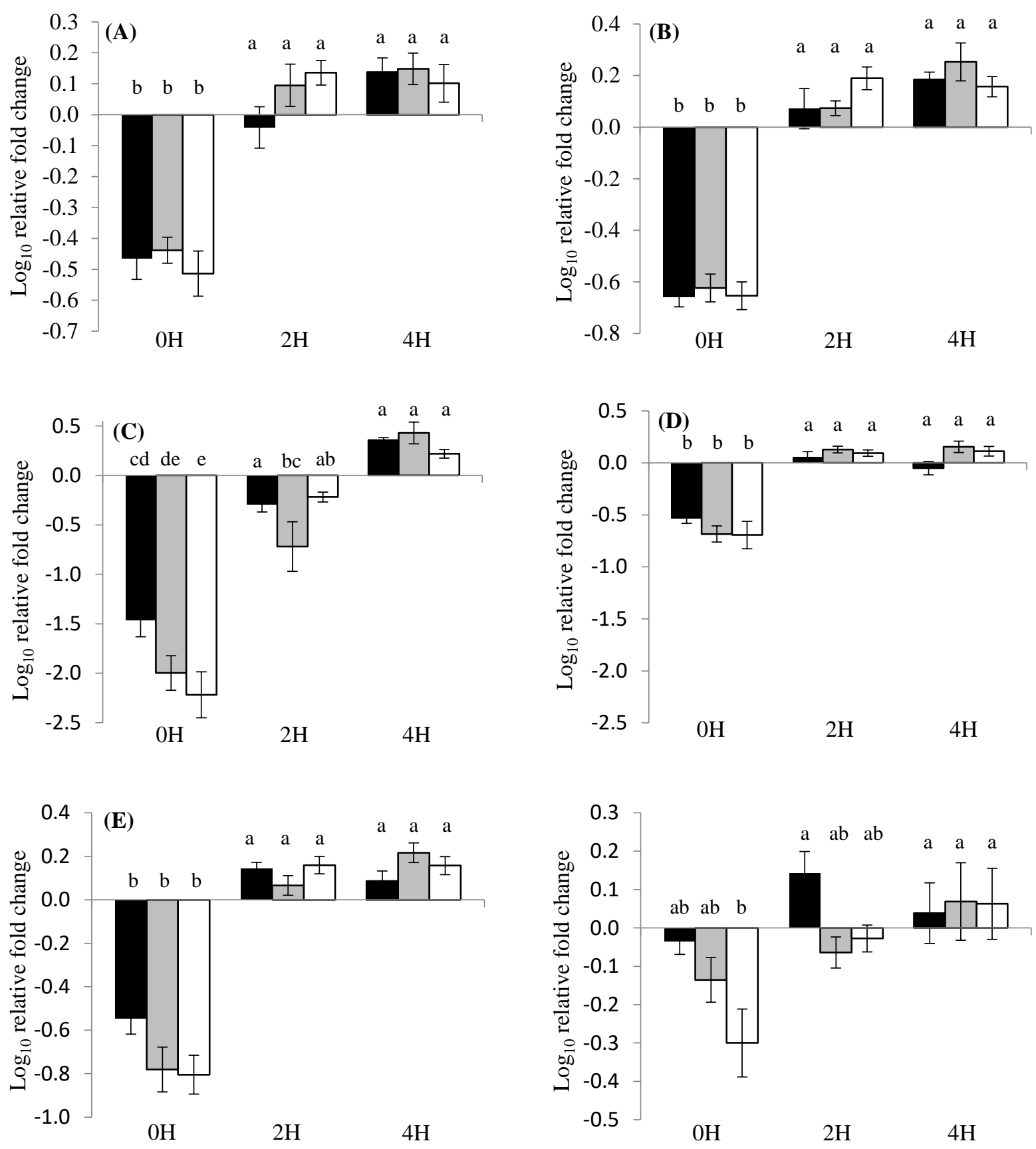

Figure 3. Transcript levels of selected genes of methionine (A, $L c$-MAT-1) and cysteine (B, $L c$-CGL) metabolic; taurine biosynthetic (C, $L c$-CSAD; D, $L c$-ADO; E, $L c$-CDO); and taurine transport (E, $L c$-TauT) pathways in the liver tissue of juvenile barramundi sampled after 24 hours starvation $(0 \mathrm{H})$; and two $(2 \mathrm{H})$ and four $(4 \mathrm{H})$ hours after ingestion of a single meal containing either a deficient (DEF), adequate (ADQ) or excessive $(\mathrm{EXC})$ dietary taurine content. Values were normalised to those of elongation factor $1 \alpha(\mathrm{Ef} 1 \alpha)$ before $\log 10$ transformation. Values presented are means $(n=6) \pm S$.E. (represented by vertical bars). Significance analyses were performed by Two-Way ANOVA followed by post-hoc analysis of means by Tukey's honestly significant difference test. Columns with the same superscript letter are not significantly different. Letters are presented in order of magnitude from largest to smallest $\log 10$ transformed relative fold change. Gene abbreviations can be found in Table 2 . 

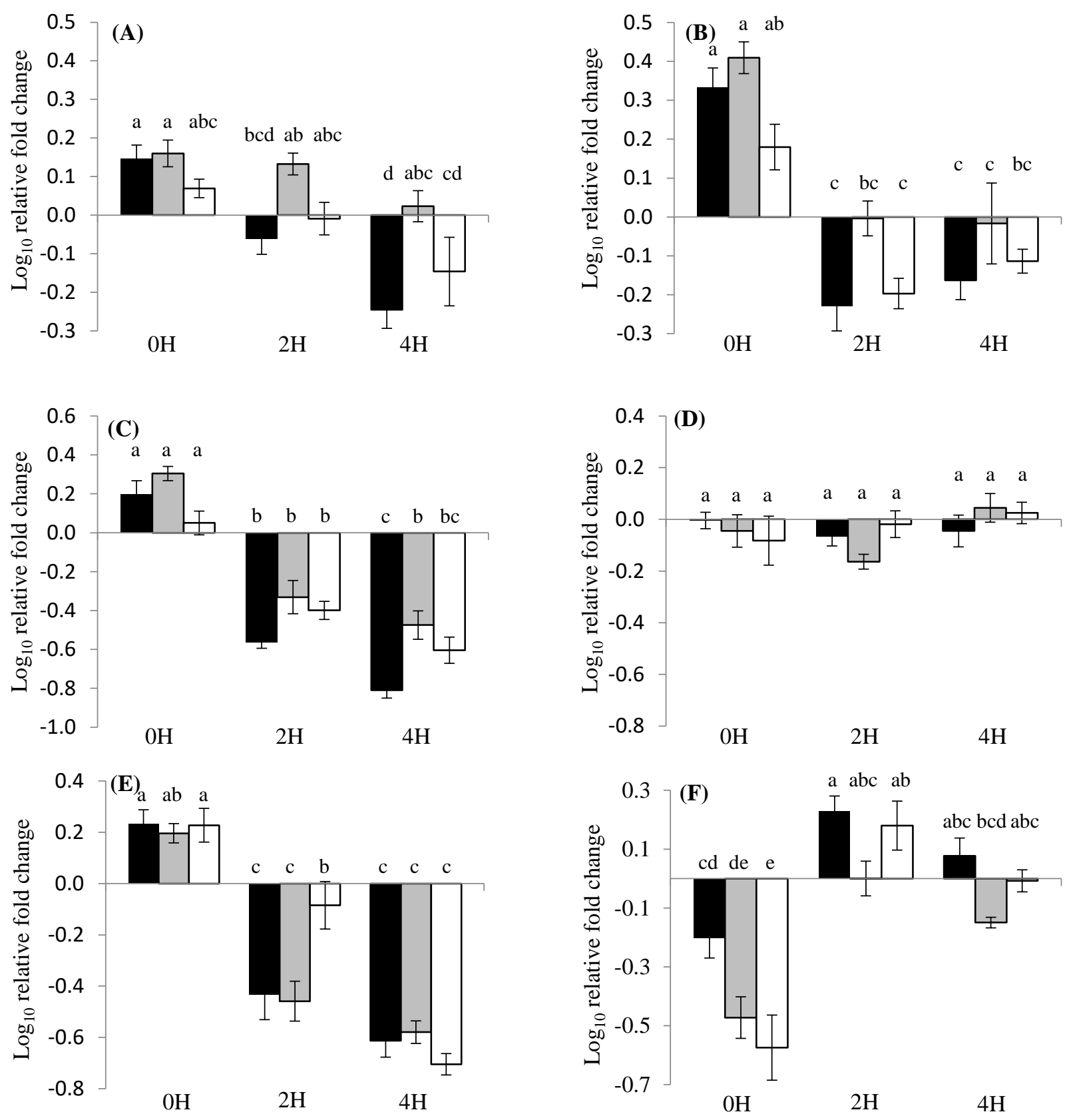

Figure 4. Transcript levels of selected genes of the somatotropic axis (A, $L c$-IGF-I; B, $L c$-IGF-II; C, $L c$ GHR-II); proteolytic pathways (D, $L c$-MUL-1; E, $L c$-ZFAND-5); and inhibition of the TOR pathway (F, $L c$ Redd-1) in the liver tissue of juvenile barramundi sampled after 24 hours starvation $(0 \mathrm{H})$; and two $(2 \mathrm{H})$ and four $(4 \mathrm{H})$ hours after ingestion of a single meal containing either a deficient (DEF), adequate (ADQ) or excessive $(\mathrm{EXC})$ dietary taurine content. Values were normalised to those of elongation factor $1 \alpha(\mathrm{Ef} 1 \alpha)$ before $\log 10$ transformation. Values presented are means $(n=6) \pm S$.E. (represented by vertical bars). Significance analyses were performed by Two-Way ANOVA followed by post-hoc analysis of means by Tukey's honestly significant difference test. Columns with the same superscript letter are not significantly different. Letters are presented in order of magnitude from largest to smallest $\log 10$ transformed relative fold change. Gene abbreviations can be found in Table 2 . 